\title{
Dynamic Behavior of AP1000 Nuclear Island Building in Japanese Kobe 1995 Earthquake
}

\author{
Dinh Kien Nguyen ${ }^{1}$, Lam Dong Vu ${ }^{1}$, Buntara S. Gan ${ }^{2 *}$ \\ ${ }^{1}$ Institute of Mechanics, Vietnam Academy of Science and Technology, Vietnam \\ ${ }^{2 *}$ Corresponding Author, Department of Architecture, College of Engineering, Nihon University, Japan
}

\begin{abstract}
This paper studies the dynamic behavior of the AP1000 nuclear island building under the action of the Japanese Kobe 1995 earthquake. A three-dimensional finite element model for the building is developed and employed in the study. The modal and dynamic analyses of the building under the safe shutdown earthquake are carried out with the help of the commercial finite element software ANSYS. The vibration characteristics, including the natural frequencies, mode shapes, and the time histories for the dynamic displacements, velocities, and accelerations of the building are computed and given in the tabular and figure forms. A comparison of the dynamic response of the building in the Kobe earthquake with that in the El Centro earthquake is carried out. The numerical result reveals that the safety of the AP1000 nuclear island building in the Kobe earthquake is much more concerned than it is subjected to the well-known El Centro 1944 earthquake.
\end{abstract}

Keywords: AP1000, nuclear island building, finite element model, Kobe earthquake, dynamic analysis.

\section{Introduction}

Dynamic analysis of nuclear power plants under earthquakes is important in the design of a nuclear power plant and evaluation of the existing plants. Due to the complexity of the nuclear structures and seismic loadings, numerical methods, especially the finite element method with its versatility in the spatial discretization, are often employed in solving this dynamic complex problem. Many investigations on the safety and dynamic behavior of nuclear power plants have been reported in the literature, contributions that are most relevant to the present work are briefly discussed below.

Manjuprasal et al. [1] studied the nonlinear response of ultimate behavior of reinforced concrete containment shell of nuclear plants under the action of one-directional seismic loading by developing a 20-node isoparametric solid finite element. The authors showed that the dynamic displacement of the structure increases considerably when the effect of material nonlinearity is taken into consideration. Tunon-Sanjur et al. [2] presented the shell and stick finite element models of AP1000 nuclear island for seismic analysis. The soilstructure interaction was considered by the authors by using the program SASSI which is enabled to handle 2D and 3D soil-structure interaction problems. Nakamura [3] proposed the transform methods of frequencydependent soil impedance to the time domain for evaluation of the seismic behavior of a deeply embedded nuclear power building. The finite element method was used in combination with Newmark method for obtaining the time histories of the vibration characteristics of the building. Also taking the interaction of soil and structure into consideration, Nakamura et al. [4] carried out a study of ultimate seismic response and fragility assessment of a nuclear power building by using a nonlinear three-dimensional finite element model. Perotti et al. [5] presented a numerical procedure based on the step-by-step dynamic integration for evaluating fragility of isolated nuclear buildings under seismic loading. Using the finite element method, Zhao and Chen [6] studied the dynamic response of a reinforced concrete containment with or without damping rubber bearing isolators under three-directional seismic loading. The structure of the nuclear power plant has been represented by a three-dimensional finite element model, and the dynamic response of the structure has been obtained with the help of the commercial finite element package ANSYS. Also by using the finite element method, Chen et al. [7] carried out a dynamic analysis of the isolated AP1000 nuclear island under a safe shutdown earthquake. It has been shown in the work that the dynamic displacements of the structure decrease considerably by using the high damping rubber bearing isolators. Various aspects of the modal and dynamic analyses of the AP1000 shield building by using the numerical method are presented in the review papers [8, 9]. Zhai et al. [10] developed a three-dimensional finite element model for the reinforced concrete containment building and employed it to study the dynamic behavior of the building under the mainshock-aftershock earthquake sequences. In order to investigate the effect of foundation embedment on the floor response spectra of nuclear power plants, Politopouos et al. [11] modeled the soil domain under the plant by the finite elements and Lysmer radiation boundaries. The authors showed that the base rocking excitation induced by soil-structure interaction, may amplify the non-isolated modes' response. Sener et al. [12] developed a 3D nonlinear inelastic finite element model and then incorporated it into the finite element software ABAQUS for studying the seismic behavior of a pressurized water reactor containment internal structure. Based on the finite element method, Xu et al. [13] 
investigated the effects of water level in a water tank on the dynamic response of the AP1000 shield building subjected to three-dimensional ground motion.

In this paper, a three-dimensional finite element model for the AP1000 nuclear island building is developed for dynamic analysis of the building under a safe shutdown earthquake. The building is assumed to be built in a hard rock base, and thus the boundary conditions at the lower part are considered to be fixed. Both the reinforced concrete and steel containments are incorporated in the finite element model at the same time herein, and this helps the model to be more realistic. The dynamic characteristics of the structure, including the natural frequencies, vibration modes, and time histories for displacements, velocities, and accelerations under the action of the Japanese Kobe 1995 earthquakes are obtained with the help of the finite element software ANSYS [14]. The dynamic response of the building under El Centro 1944 earthquake is also computed, and the behavior of the structures in the two earthquakes is compared and discussed.

\section{Finite element model of AP1000 nuclear island}

The AP1000 is an advanced nuclear power plant based on the concepts of passive safety. The plant is a standard design by Westinghouse and its partners, and the design has been certified by US Nuclear Regulatory Commission based on the review of seismic analysis at hard rock site. The AP1000 plant, as shown in Fig. 1, has five main buildings, namely the nuclear island building, the turbine building, the diesel generator building, the radwaste building and the annex building. Among these five buildings, the safety of the nuclear island building under earthquakes is the most concerned in the design of the plant.

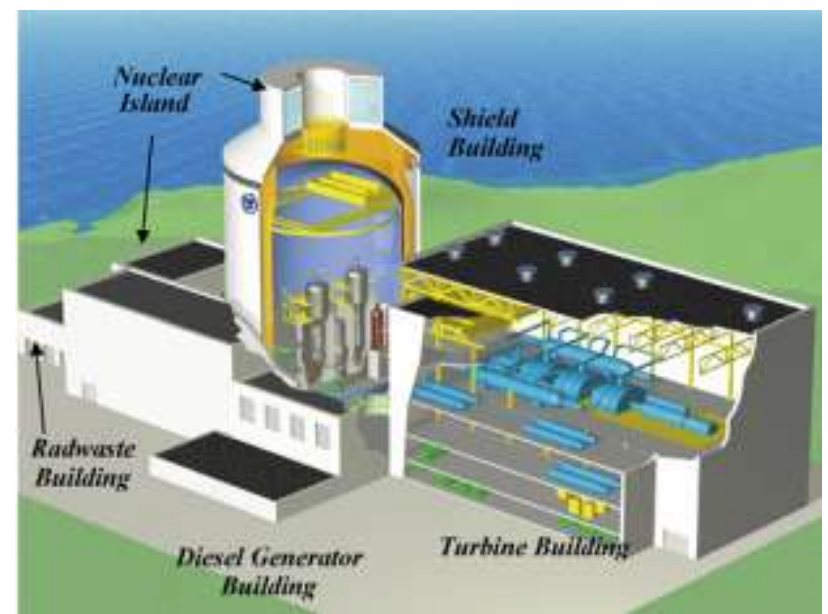

Figure 1: Principle buildings of AP1000 nuclear plant [2]

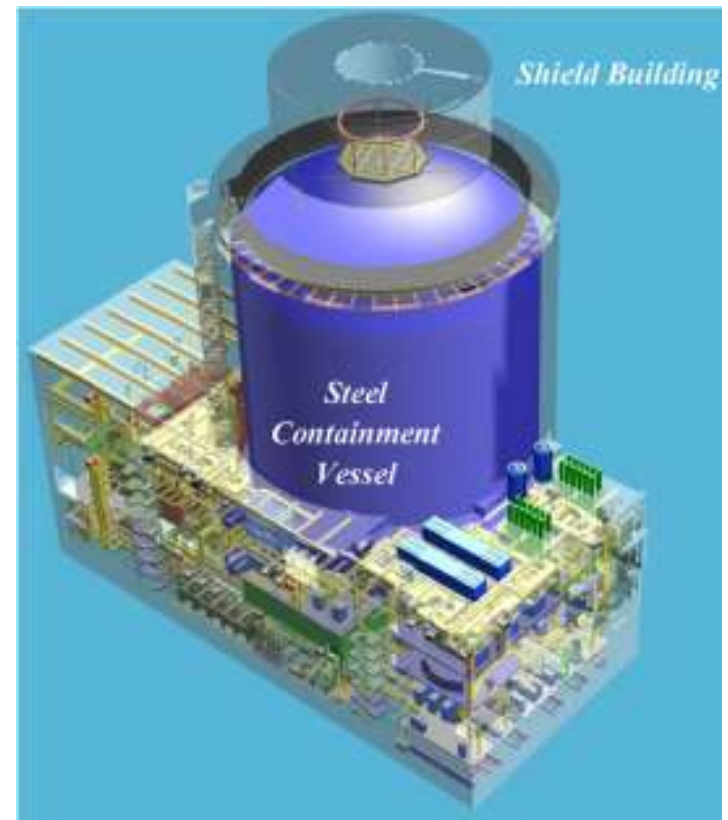

Figure 2: AP1000 nuclear island building [2] 
The nuclear island building of the AP1000 plant, as depicted in Fig. 2, consists of the containment building (the steel containment vessel and the internal containment structure), the shield building and the auxiliary building. The dimension of the nuclear island used in the present analysis is $77.5 \mathrm{~m} \times 35 \mathrm{~m}$ with a wall thickness of $0.9 \mathrm{~m}$. The shield building has a height of $83 \mathrm{~m}$, the outer radius of $44 \mathrm{~m}$, and the thickness of $0.04 \mathrm{~m}$. The properties of the concrete and steel reinforcement are given in Table 1.

Table 1. Material properties of AP1000 nuclear island building

\begin{tabular}{|l|l|l|}
\hline \multicolumn{1}{|c|}{ Property } & Concrete & Steel reinforcing bar \\
\hline Density $\left(\mathrm{kg} / \mathrm{m}^{3}\right)$ & 2300 & 7800 \\
Young's modulus $(\mathrm{MPa})$ & $3.5 \times 10^{4}$ & $2.1 \times 10^{5}$ \\
Poisson's ratio & 0.2 & 0.3 \\
Damping ratio (\%) & 5 & 5 \\
\hline
\end{tabular}
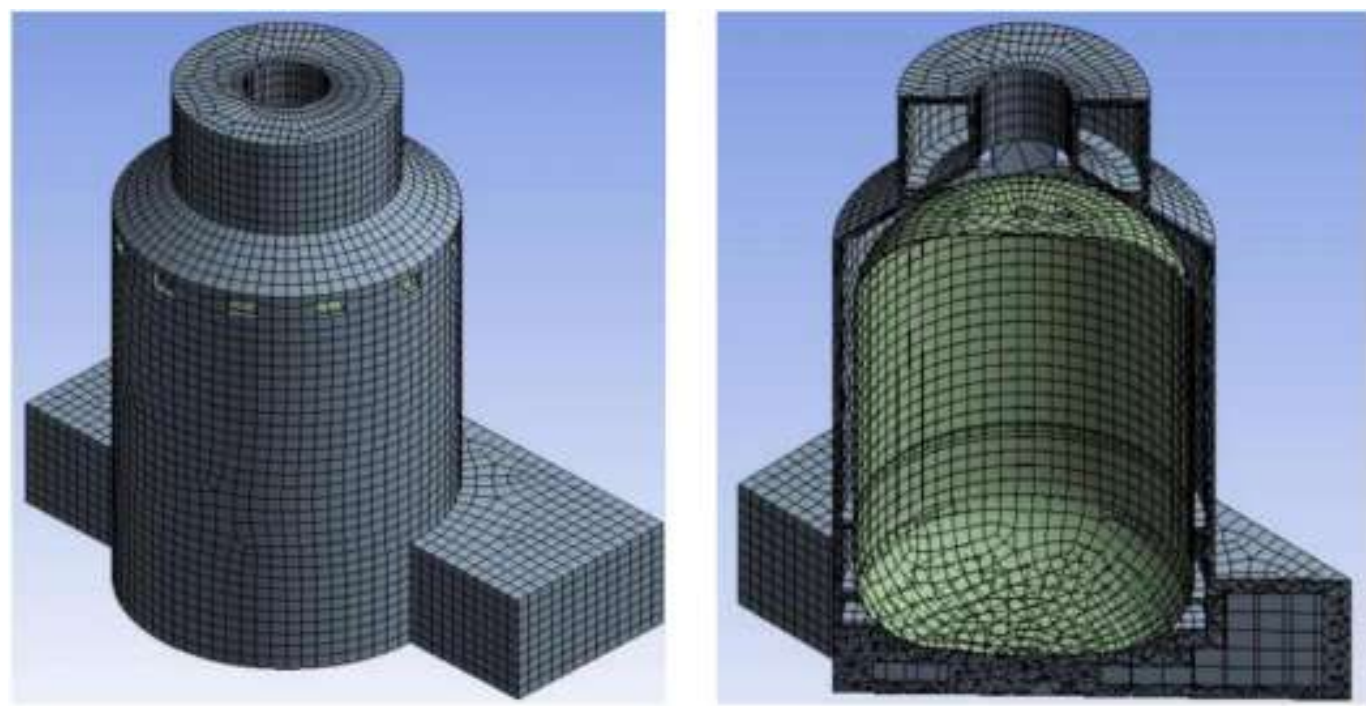

Figure 3: Three-dimensional finite element model of AP1000 nuclear island building

A three finite element model of the AP1000 nuclear island is developed by using ANSYS R15.0. The model consists of shell and brick elements, in which the shell elements are used to model the steel containment vessel and shield building, whereas other parts are modeled by solid elements. The interface between the upper part of the building and the base mat as well as between the walls of the building and the upper base mat are modeled by the share node option of ANSYS. The convergence of the mesh size is carried out to find out an acceptable mesh. Finally, a mesh with a total number of 88349 elements, in which 2192 elements are the share contact elements, is decided to use in the analysis.

\section{Seismic finite element analysis}

The effect of the material nonlinearity is not considered in the present work, and the linear dynamic analysis is carried out for the nuclear island structure. The equations of motion of a linear structure subjected to seismic loading can be written in the context of finite element analysis as follows $[15,16]$

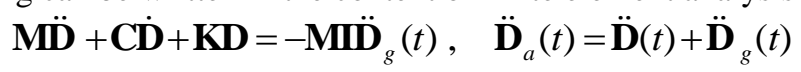

where $\mathbf{D}, \dot{\mathbf{D}}, \ddot{\mathbf{D}}, \ddot{\mathbf{D}}_{g}, \ddot{\mathbf{D}}_{a}$ are, respectively, the vectors of relative nodal displacements, relative nodal velocities, relative nodal accelerations, ground accelerations and absolute nodal accelerations; $\mathbf{M}, \mathbf{C}$ and $\mathbf{K}$ are the mass, damping and stiffness matrices of the structures, respectively. The vector $\mathbf{I}$ in (1) is the influence coefficient vector, having 1 for elements corresponding to degrees of freedom in the direction of the applied ground motion and zero for the other degrees of freedom [16]

Rayleigh damping is used herein to simulate the structural damping. Thus, the damping matrix $\mathbf{C}$ is computed from the structural stiffness and mass matrices as

$$
\mathbf{C}=\alpha \mathbf{K}+\beta \mathbf{M}
$$

where $\alpha$ and $\beta$ are, respectively, the mass and stiffness proportional Rayleigh damping coefficients, which are calculated from the critical damping ratio and the structural natural frequencies as [17]

$$
\alpha=2 \xi \frac{\omega_{1} \omega_{2}}{\omega_{1}+\omega_{2}}, \quad \beta=\frac{2 \xi}{\omega_{1}+\omega_{2}}
$$


where $\xi$ is the critical damping ratio, assumed to be of $5 \%$ in the present work; $\omega_{1}$ and $\omega_{2}$ are the natural frequencies, which are chosen to bound the design spectrum. In the current work, $\omega_{1}$ is selected as the fundamental frequency and a frequency of $30 \mathrm{~Hz}$ is chosen for the upper-frequency $\omega_{2}$ because the spectral contents of seismic design are insignificant above this frequency [17].

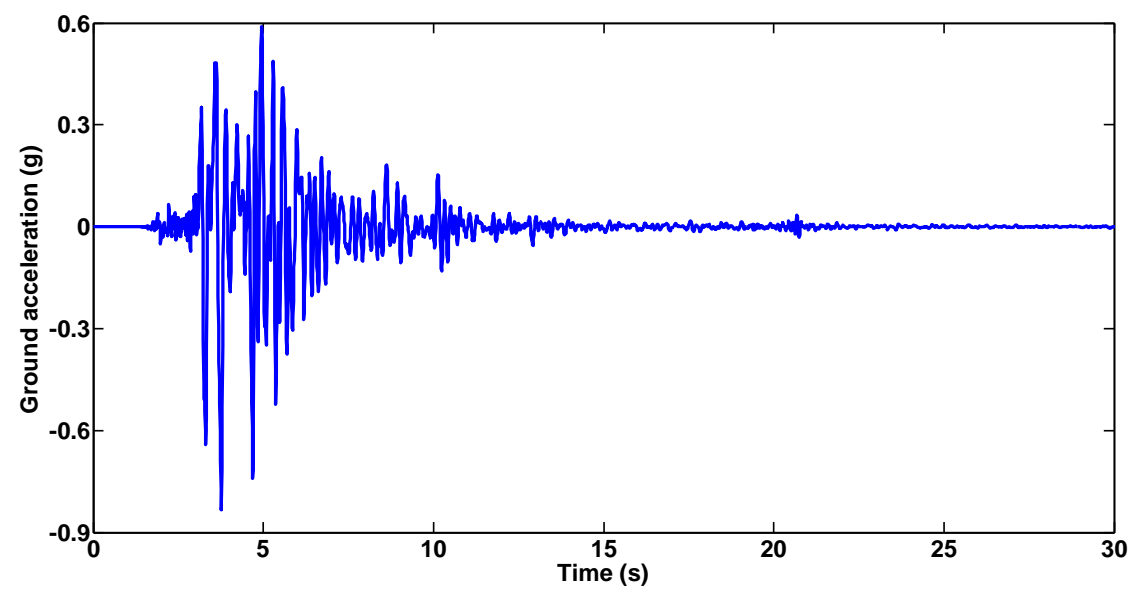

Figure 4: N-S component of ground acceleration of Kobe 1995 earthquake

To understand the dynamic response of the nuclear island building and to evaluate its dynamic characteristics, the acceleration time history of the earthquake is applied at the base of the building. In the present work, the seismic excitation is represented by one artificial N-S component. This ground motion represents the assumed safe shutdown earthquakes at hypothetical embedment in stiff rock. The ground acceleration of Kobe 1995 earthquake, which is used as input ground acceleration data in the present work, is depicted in Fig. 4.

\section{Results and discussion}

Due to the cost and complex geometry of the nuclear building, it is very difficult to perform a modal test for the real down-scaled structure, and a finite element modal analysis is preferable. The modal analysis is obtained by solving the free vibration equations of the structure without the damping effect. To this end, the damping matrix $\mathbf{C}$ and the nodal force vector in the equation of motion are set to zero, and (1) reduces to the simple form

$$
\mathbf{M} \ddot{\mathbf{D}}+\mathbf{K D}=\mathbf{0}
$$

The above equation leads to an eigenvalue problem, and its solution gives the natural frequencies and vibration modes of the structure. Fig. 5 shows the first two vibrations modes of the building obtained from the modal analysis. The corresponding natural frequencies to these modes are $3.6219 \mathrm{~Hz}$ and $3.6294 \mathrm{~Hz}$, respectively. These natural frequencies are very close to the value obtained by Chen et al. in Ref. [7]. Noting that the effect of the steel containment has not been taken into consideration in [7], and this may be explained by the slight difference between the results of the finite element modal analysis of this paper with that of Ref. [7].
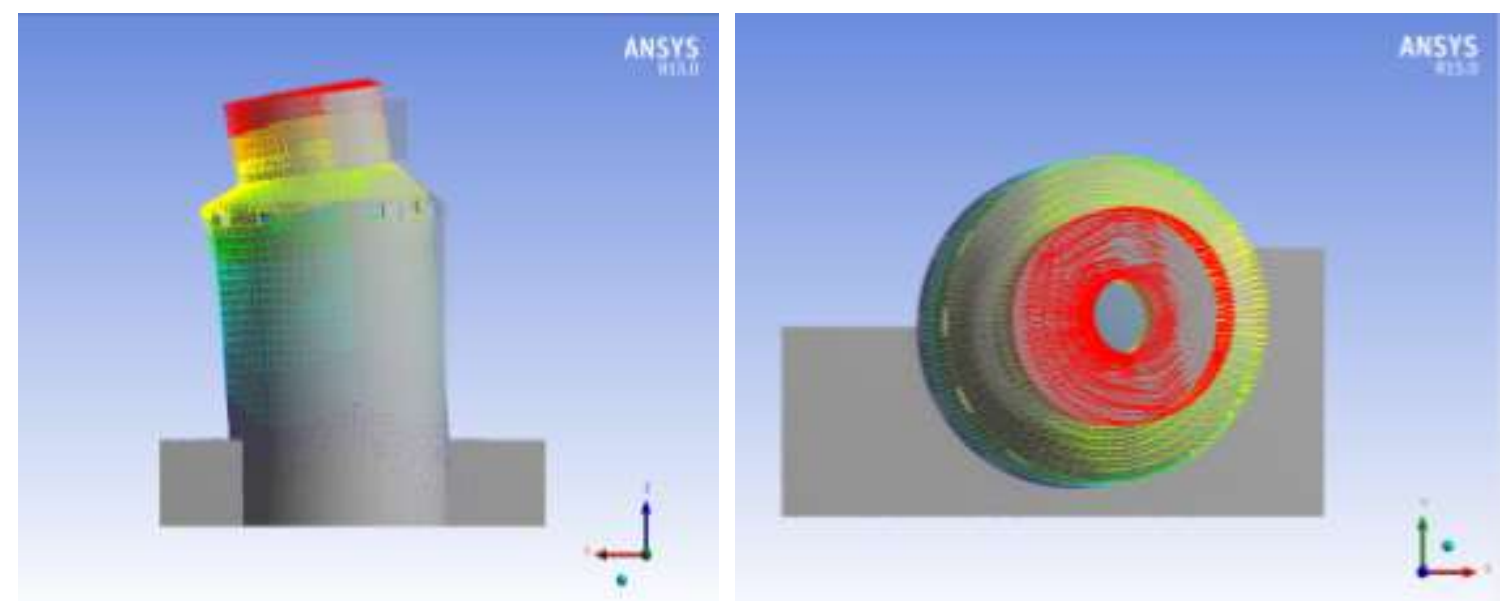

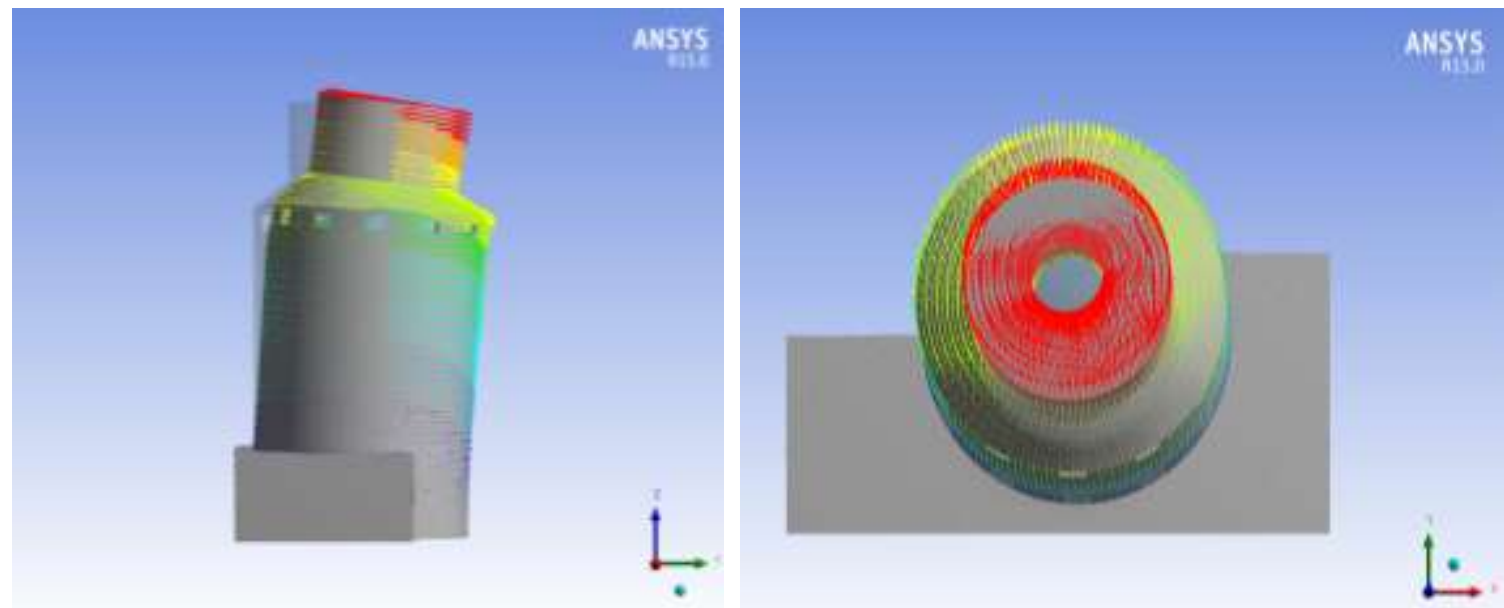

Figure 5: The first two vibration modes of the nuclear island building

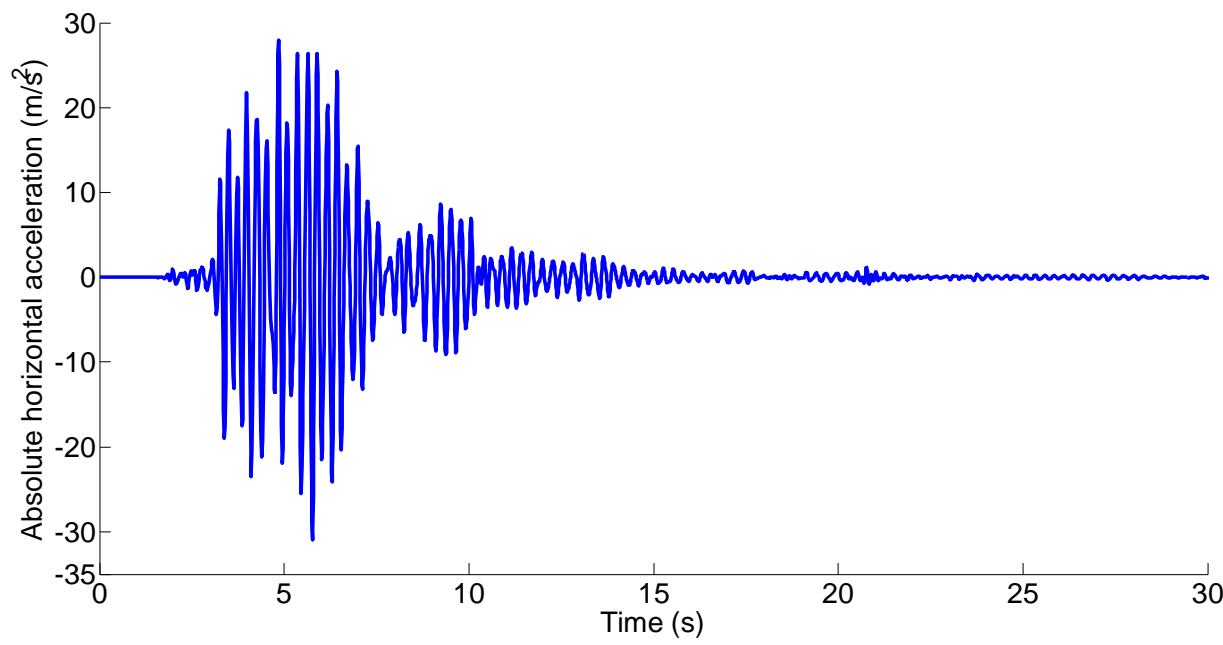

Figure 6: Absolute acceleration response at the top point of nuclear island building

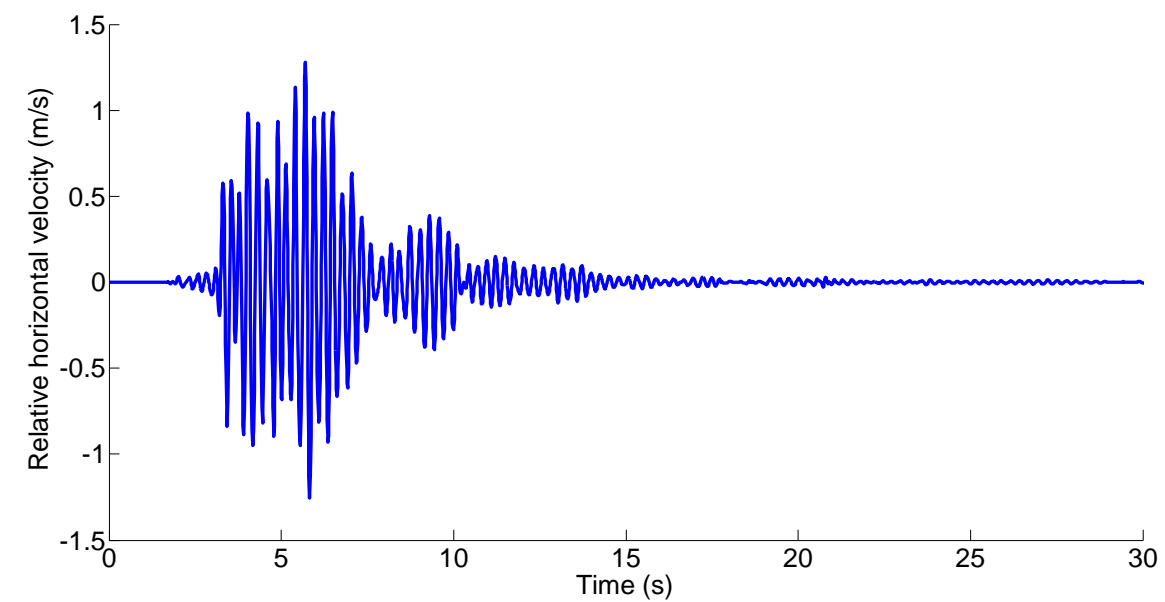

Figure 7: Relative velocity response at the top point of nuclear island building

The dynamic response of absolute horizontal acceleration and relative velocity at the top point of the nuclear island building under the safe shutdown Kobe earthquake is depicted in Fig. 6 and Fig. 7, respectively. The maximum and minimum accelerations at the point are $27.9940 \mathrm{~m} / \mathrm{s}^{2}$ and $-30.9320 \mathrm{~m} / \mathrm{s}^{2}$, and these critical values attain at the $4.8512 \mathrm{~s}$ and $5.7657 \mathrm{~s}$, respectively. The corresponding values for the relative horizontal velocity are $1.2792 \mathrm{~m} / \mathrm{s}$ and $-1.2530 \mathrm{~m} / \mathrm{s}$, occurred at $5.6886 \mathrm{~s}$ and $5.8171 \mathrm{~s}$, respectively. For ground 
acceleration history of the Kobe earthquake in Fig. 4, the peak ground acceleration is $0.8180 \mathrm{~g}$, occurred at $3.670 \mathrm{~s}$, and thus the peak acceleration and velocity response occurred a bit later after the peak ground motion. This delay of the dynamic response can be explained by the damping effect considered herein. Another remark can be seen from Figs. 6 and 7 are that the acceleration and velocity response contributes mainly in the range of the $3^{\text {rd }}$ and $10^{\text {th }}$ seconds, the period of the large ground acceleration. The acceleration and velocity at the point decrease rapidly after $10^{\text {th }}$ second and they almost disappear after the $15^{\text {th }}$ second.

In Fig. 8, the time history for the relative horizontal displacement at the top point of the nuclear island building under the Kobe earthquake is illustrated. As seen from the figure, the building displaces horizontally during the earthquake. The structure oscillates considerably between $-5.2869 \mathrm{~cm}$ and $5.7833 \mathrm{~cm}$ in the $x$-direction in the $3^{\text {rd }}$ and $10^{\text {th }}$ second period. As in case of the acceleration and velocity, the relative displacement at the top point of the building decays rapidly after $10^{\text {th }}$ second, and the oscillation of the building is hardly recognized after the $15^{\text {th }}$ second.

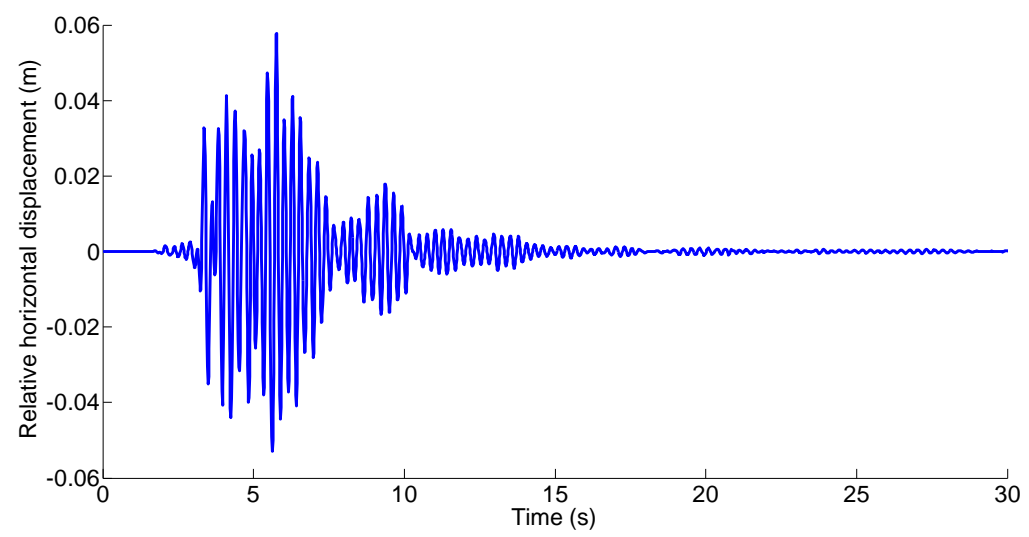

Figure 8: Time history of relative displacement at the top point of nuclear island

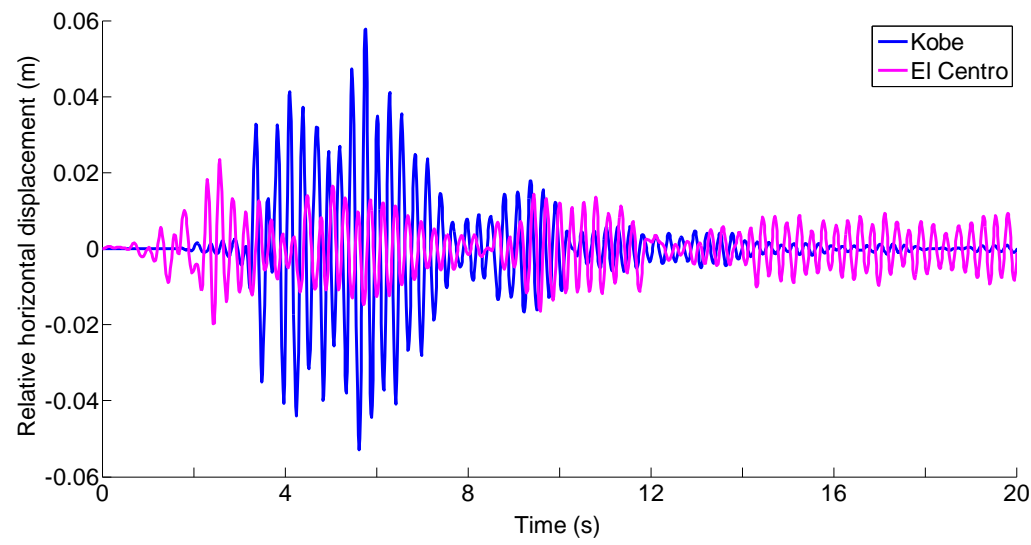

Figure 9: Relative horizontal displacements response at the top point of nuclear island under Kobe and El Centro earthquakes

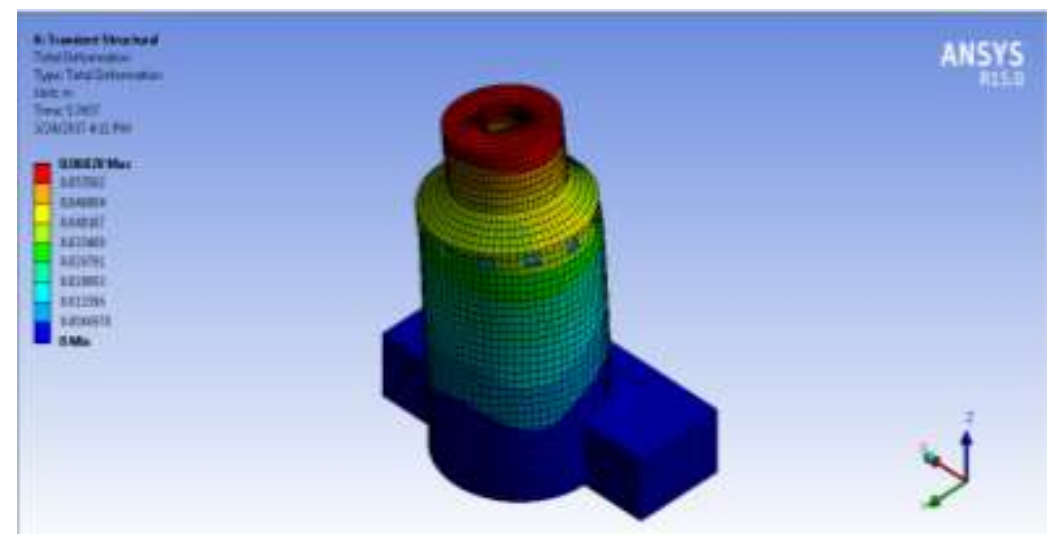




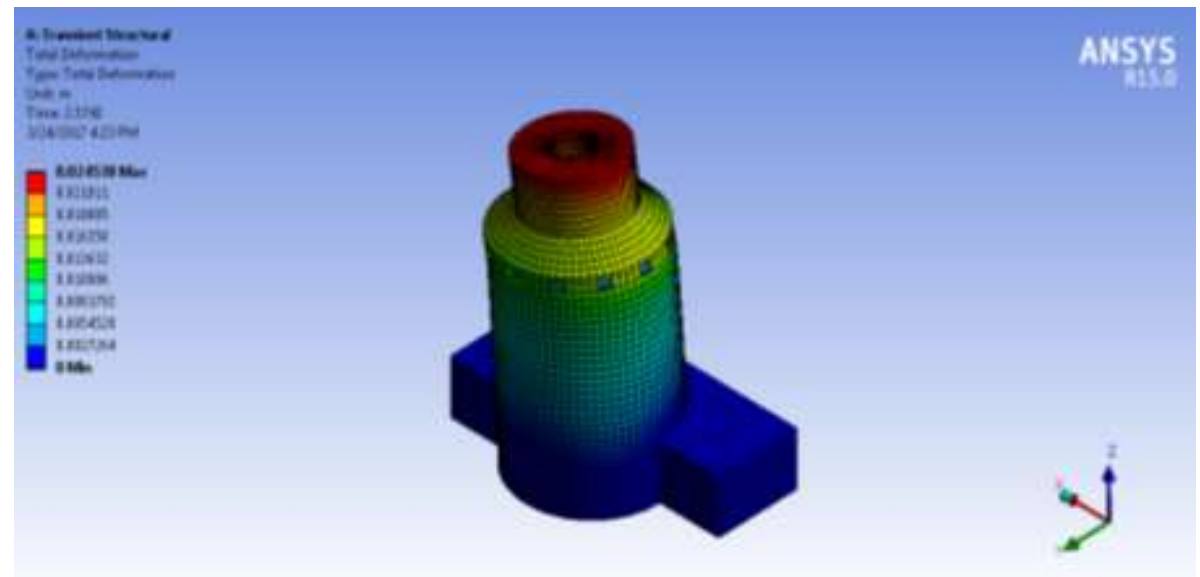

Fig. 10: Deformed configurations of the nuclear island building at the maximum displacements of Kobe earthquake (upper) and El Centro 1944 (lower)

Table 2: The critical values and corresponding times of dynamic response of nuclear island building under Kobe 1995 and El Centro 1944 earthquakes

\begin{tabular}{|l|l|l|l|l|l|l|}
\hline \multirow{2}{*}{$\begin{array}{l}\text { Earthquake } \\
\text { name }\end{array}$} & \multicolumn{2}{|l|}{ Relative displacement } & \multicolumn{2}{l|}{ Relative velocity } & \multicolumn{2}{l|}{ Absolute acceleration } \\
\cline { 2 - 7 } & $\begin{array}{l}\text { Max }(\mathrm{m}) \\
(\text { Time, } \mathrm{s})\end{array}$ & $\begin{array}{l}\text { Min }(\mathrm{m}) \\
(\text { Time, } \mathrm{s})\end{array}$ & $\begin{array}{l}\text { Max }(\mathrm{m} / \mathrm{s}) \\
(\text { Time }, \mathrm{s})\end{array}$ & $\begin{array}{l}\text { Min }(\mathrm{m}) \\
(\text { Time, } \mathrm{s})\end{array}$ & $\begin{array}{l}\text { Max }\left(\mathrm{m} / \mathrm{s}^{2}\right) \\
(\text { Time, } \mathrm{s})\end{array}$ & $\begin{array}{l}\text { Min }\left(\mathrm{m} / \mathrm{s}^{2}\right) \\
(\text { Time, } \mathrm{s})\end{array}$ \\
\hline Kobe & $5.7833 \times 10^{-2}$ & $-5.2869 \times 10^{-2}$ & 1.2792 & -1.2530 & 27.9940 & -30.9320 \\
& $(5.7657)$ & $(5.6244)$ & $(5.6886)$ & $(5.8171)$ & $(4.8512)$ & $(5.7657)$ \\
\hline El Centro & $2.3512 \times 10^{-2}$ & $-1.9847 \times 10^{-2}$ & 0.56181 & -0.41577 & 12.659 & -11.999 \\
& $(2.5742)$ & $(2.4346)$ & $(2.5142)$ & $(2.3774)$ & $(2.464)$ & $(2.5742)$ \\
\hline
\end{tabular}

In order to evaluate the dynamic behavior of the nuclear island building in some more further, the dynamic response of the building under the well-known El Centro 1944 earthquake is also analyzed. In Fig. 9 the relative displacement response at the top point of the building is shown for both the Kobe 1995 and El Centro 1944 earthquakes. As seen from the figure, for the first ten seconds, the building oscillates much stronger in the Kobe earthquake that it does in the El Centro earthquake. However, the situation is different for the last ten seconds, and the structure vibrates more strongly in the El Centro earthquake that it does in the Kobe earthquake. Fig. 10 shows the deformed configurations of the building in the two earthquakes at the time corresponding to the largest horizontal displacements. The building, as seen from the figure, deforms more strongly in the Kobe earthquake that it does in the El Centro earthquake. In Table 2, the maximum and minimum values of the relative displacement, velocity and absolute acceleration at the top point of the building in the two earthquakes are listed. The times at which these critical values occurred are also given in the table. The safety of the building subjected to the Kobe 1995 earthquake, as seen from the Table, is more concerned than when it is subjected to the El Centro 1944 earthquake. The maximum and minimum values of the displacement, velocity and acceleration at the top point of the building under the Kobe earthquake, as seen from Table 2, are more than two times larger than that of the building under the El Centro earthquake. In other words, the nuclear island building is more dangerous when it is under the action of the Japanese Kobe 1995 earthquake than under the American El Centro 1944 earthquake.

\section{Conclusions}

The dynamic behavior of the AP1000 nuclear island building under Japanese Kobe 1995 earthquake has been investigated. A three-dimensional finite element model was developed and employed in the investigation. The dynamic characteristics of the building, including the natural frequencies, vibration modes and time histories for the displacement, velocity and acceleration have been obtained with the aid of the finite element software ANSYS. In order to evaluate the dynamic behavior of the building in the Kobe earthquake, the dynamic response of the structure under the well-known El Centro earthquake was also computed. The obtained results show that with the dynamic response of the nuclear island building in the Kobe earthquake is more than two times larger than that of the building in the El Centro earthquake, the safety of the building in the Kobe earthquake is much more concerned than it is in the El Centro earthquake. It is necessary to note that the effects of material nonlinearity and the soil-structure interaction have not been taken into consideration in the present work, and more works are necessary to carry out to examine the effect of these parameters on the dynamic response of the nuclear island building subjected to seismic loading. 


\section{Acknowledgements}

The research described in this article has been supported by Grant VAST01.06/16-17.

\section{References}

[1] M. Manjuprasad, S. Gopalakrishnan, and T.V.S.R. Appa Rao, Non-linear dynamic response of a reinforced concrete secondary containment shell subjected to seismic load, Engineering Structures, 23(5), 2001, 397-406.

[2] L.Tunon-Sanjur, R.S. Orr, S. Tinic, and D.P. Ruiz, Finite element modeling of the AP1000 nuclear island for seismic analyses at generic soil and rock sites, Nuclear Engineering and Design, 237(12-13), 2007, 1474-1485.

[3] N. Nakamura, Seismic response analysis of deeply embedded nuclear reactor buildings considering frequency-dependent soil impedance in time domain, Nuclear Engineering and Design, 238(7), 2008, 1845-1854.

[4] N. Nakamura, S. Akita, T. Suzuki, M. Koba, S. Nakamura, and T. Nakano, Study of ultimate seismic response and fragility evaluation of nuclear power building using nonlinear three-dimensional finite element model, Nuclear Engineering and Design, 240(1), 2010, 166-180.

[5] F. Perotti, M. Domaneschi, and S. De Grandis, The numerical computation of seismic fragility of base-isolated Nuclear Power Plants buildings, Nuclear Engineering and Design, 262, 2013. 189-200.

[6] C. Zhao, and J. Chen, Numerical simulation and investigation of the base isolated NPPC building under three-directional seismic loading, Nuclear Engineering and Design, 265, 2013, 484-496.

[7] I. Chen, C. Zhao, Q. Xu, and C. Yuan, Seismic analysis and evaluation of the base isolation system in AP1000 NI under SSE loading, Nuclear Engineering and Design, 278, 2014, 117-133.

[8] C. Zhao, and J. Chen, Dynamic characteristics of AP1000 shield building for various water levels and air intakes considering fluidstructure interaction, Progress in Nuclear Energy, 70, 2014, 176-187.

[9] C. Zhao, J. Chen, and Q. Xu, Dynamic analysis of AP1000 shield building for various elevations and shapes of air intakes considering FSI effects subjected to seismic loading, Progress in Nuclear Energy, 74, 2014, 44-52.

[10] C.-H. Zhai, Z. Zheng, S. Li, and L.-L. Xie, Seismic analyses of a RCC building under mainshock-aftershock seismic sequences, Soil Dynamics and Earthquake Engineering, 74, 2015, 46-55.

[11] I . Politopouos, I. Sergis, and F. Wang, Floor response spectra of a partially embedded seismically isolated nuclear plant, Soil Dynamics and Earthquake Engineering, 78, 2015, 213-217.

[12] K.C. Senera, A.H. Varma, P.N. Bootha, and R. Fujimoto, Seismic behavior of a containment internal structure consisting of composite SC walls, Nuclear Engineering and Design, 295, 2015, 804-816.

[13] Q. Xu, J. Chen, C. Zhang, J. Li, and C. Zhao, Dynamic analysis of AP1000 shield building considering fluid and structure interaction effects, Nuclear Engineering and Technology, 48(1), 2016, 246-258.

[14] Inc, A., 2013. ANSYS Release 15.0 (Canonsburg, PA, USA).

[15] A. K. Chopra, Dynamics of structures, theory and applications to earthquake engineering (4 ${ }^{\text {th }}$ edition, Boston: Prentice Hall, 2014).

[16] T.K. Datta, Seismic analysis of structures (Singapore: John Wiley \& Sons Pte Ltd, 2010).

[17] R.D. Cook, D.S. Malkus, and M.E. Plesha, Concepts and applications of finite element analysis ( $3^{\text {rd }}$ edition, New York: John Wiley \& Sons, 1989). 